\title{
Impact of obstructive sleep apnea on cognitive performance
}

\author{
Felipe Cunha Bawden' ${ }^{1}$ Cristiane Assis Oliveira², Paulo Caramelli, ${ }^{1,3}$
}

\begin{abstract}
Objective: To evaluate the impact of obstructive sleep apnea (OSA) on cognition. Method: We compared the performance of 17 patients with polysomnographic diagnosis of OSA in brief cognitive tests to that of 20 healthy controls, matched for age and education. The testing battery included the Mini-Mental State Examination (MMSE), Brief Cognitive Screening Battery (BCSB), Digit-Symbol (DS) and Phonemic Verbal Fluency (FAS). Anthropometric measures and scores from the Epworth Sleepiness Scale were also recorded. Results: OSA patients performed significantly worse than controls in the MMSE, in memory items from the BCSB, in DS and also in FAS. OSA patients also exhibited higher body mass index, increased neck circumference and higher scores in Epworth Sleepiness Scale than controls. Conclusion: OSA significantly impairs cognitive performance, especially within the domains of attention, memory and executive functioning. These deficits may be detected by brief and easy-to-administer cognitive tests.
\end{abstract}

Key words: sleep disorders, obstructive sleep apnea, excessive daytime sleepiness, cognitive performance.

\section{Impacto da apnéia obstrutiva do sono sobre a cognição}

\section{RESUMO}

Objetivo: Avaliar o impacto da apnéia obstrutiva do sono (AOS) sobre a cognição. Método: Dezessete pacientes com diagnóstico polissonográfico de AOS foram submetidos a testes cognitivos breves e seu desempenho, comparado ao de 20 controles saudáveis, emparelhados por idade e escolaridade. Os testes realizados foram MiniExame do Estado Mental (MEEM), Bateria Breve de Rastreio Cognitivo (BBRC), DígitoSímbolo (DS) e Fluência Verbal Fonêmica (FAS). Medidas antropométricas e da Escala de Sonolência de Epworth também foram coletadas. Resultados: Pacientes com AOS tiveram desempenho significativamente pior que controles no MEEM, em itens de memória da BBRC, no DS e no FAS. Pacientes também exibiram maior índice de massa corpórea, maior circunferência cervical e maior pontuação na escala de sonolência de Epworth que os controles. Conclusão: A AOS compromete significativamente o desempenho cognitivo, especialmente em atenção, memória e funções executivas. Estes déficits podem ser detectados por testes breves e de fácil aplicação.

Palavras-chave: transtornos do sono, apnéia obstrutiva do sono, sonolência excessiva diurna, desempenho cognitivo.

Obstructive sleep apnea (OSA) is a disorder associated with episodic sleep disruptions in airway patency, followed by reduction of oxygen saturation and arousals throughout the night. In result of the chronic deprivation of sleep which it determines, OSA can lead to impairment of productivity at work, traffic accidents and also to endocrine and cardiovascular diseases ${ }^{1-5}$.

The prevalence of OSA is estimated to range from $2 \%$ to $4 \%$ of the population aged 30 to 60 years, according to the first major US population-based study con-
Paulo Caramelli

Av. Prof. Alfredo Balena 190 / sala 246

30130-100 Belo Horizonte MG - Brasil

E-mail: caramelli@ufmg.br

Received 21 March 2011

Accepted 11 April 2011
'MD, MSc. Programa de Pós-Graduação em Neurociências, Universidade Federal de Minas Gerais, Belo Horizonte MG, Brazil; ${ }^{2} \mathrm{MD}$. Laboratório de Sono, Hospital Belo Horizonte, Belo Horizonte MG, Brazil; ${ }^{3} \mathrm{MD}$, PhD. Departamento de Clínica Médica, Faculdade de Medicina da Universidade Federal de Minas Gerais, Belo Horizonte MG, Brazil. 
ducted in $1993^{6-8}$. Risk factors include advanced age, male gender, obesity and craniofacial morphology $y^{6-8}$. The nightly use of positive pressure in the upper airway provided by Continuous Positive Airway Pressure (CPAP) or Bilevel Positive Airway Pressure (BiPAP) is the most effective treatment of OSA. Weight loss, abstinence from alcohol and sedatives, to prevent supine sleeping and nasal steroids in patients with concurrent rhinitis constitute behavioral measures which are potentially beneficial for all cases of OSA ${ }^{6,9}$. Oral appliance therapy is also a treatment option for patients with mild to moderate disease, as well as for those patients with severe disease who are unable to tolerate CPAP therapy ${ }^{9,10}$. Upper-airway surgery can be an alternative treatment in selected cases, but its role remains unclear. There is no current effective drug treatment for OSA, although modafinil can be used as adjuvant to reduce the symptoms of residual daytime sleepiness despite the adequate CPAP use ${ }^{6,9}$.

There is still no consensus on the mechanisms by which OSA affects cognitive performance. Excessive daytime sleepiness (EDS) is the most common symptom observed during wakefulness in these patients, which may have induced the initial studies to consider cognitive impairment as being entirely secondary to EDS. More recent investigations, however, have shown that neuronal damage determined by intermittent hypoxia may affect performance on neuropsychological tests ${ }^{11}$. This theory has been recently supported by a study using functional neuroimaging associated with neuropsychological testing in patients with OSA ${ }^{12}$.

In the present study we aimed to investigate the effects of OSA on the performance in brief cognitive tests assessing attention and executive functions, comparing the performance of patients with polysomnographic diagnosis of OSA with healthy controls.

\section{METHOD}

Patients consecutively submitted to polysomnography between October 2009 and January 2010 in the sleep laboratory of the Hospital Belo Horizonte, in Belo Horizonte MG, Brazil, who were suspected to have OSA were invited to participate in the study. Exclusion criteria included ages out of the range of 18 to 59 years, illiteracy or marked visual impairment. Shortly before implantation of electrodes, while in the waiting rooms, patients were evaluated. The study protocol initially included the measurement of anthropometric data (weight, height and neck circumference). Then, patients were submitted to four brief cognitive tests, a self-administered questionnaire of sleepiness (Epworth Sleepiness Scale) and polysomnography.

A group of healthy individuals without evidence of EDS (demonstrated by a score $<9$ on the Epworth Sleep- iness Scale) were recruited in the community to constitute a control group. These individuals underwent the same procedures described for the OSA group, except for polysomnography. The same exclusion criteria adopted for patients were employed for controls.

The study was approved by the Ethics Committee in Research of the Federal University of Minas Gerais and all participants signed an informed consent before the evaluation.

\section{Cognitive tests}

Digit-Symbol Test (DST) - DST is part of the Wechsler Adult Intelligence Scale (WAIS) and provides a measure of psychomotor performance, motor persistence, sustained attention, response speed and visuospatial coordination, with results accepted as independent of intelligence $^{13}$. It consists on nine digit-symbol pairs followed by a list of digits. Under each digit the subject should write down the corresponding symbol as fast as possible. The number of correct symbols within the allowed time (120 sec) is measured.

Mini-Mental State Examination (MMSE) - The MMSE is a worldwide used screening tool for global cognitive assessment ${ }^{13-15}$. The test investigates temporal and spatial orientation, memory (immediate and delayed recall), attention, calculation skills, language and constructive praxis. The score ranges from 0 to 30 points, with higher scores corresponding to better performance.

Brief Cognitive Screening Battery (BCSB) - It consists of three presentations of 10 figures drawn on a sheet of paper, with assessment of incidental memory, immediate memory and learning, a delayed recall after a brief interference represented by category fluency (animals per minute) and clock drawing tests, and recognition. Thus, the BCSB provides five measures related to memory (incidental, immediate, learning, delayed recall and recognition), language, semantic memory and executive functions ${ }^{16}$.

Phonemic Verbal Fluency (FAS) - This test assesses verbal fluency for the production of words beginning with letters "F", "A" and "S" (one minute for each letter).

\section{Epworth Sleepiness Scale (ESS)}

The ESS is a self-administered questionnaire and refers to the possibility of falling asleep in eight different situations of everyday life ${ }^{17,18}$. The likelihood of napping is quantified with a scale ranging from 0 (zero) to 3 (three), where 0 corresponds to none and three, the most likely to doze. Scores greater than 10 suggest a high possibility of EDS. Scores over 16 are indicative of severe sleepiness, more commonly found in patients with moderate or severe OSA, narcolepsy, or idiopathic hypersomnia ${ }^{18}$. 


\section{Polysomnography}

Polysomnography is the procedure dedicated to monitor multiple physiological parameters during sleep ${ }^{6,19,20}$. The measurements included in this study were sleep electroencephalography, electrooculography, chin and leg eletromyography, eletrocardiography, and recordings of airflow (thermistor and nasal pressure monitor), repiratory effort (strain gauges), oxygen saturation, body position and snore microphone. A technician was in constant attendance. OSA was classified as mild (5 to 15 respiratory events per hour), moderate (as greater than 15 to 30 events per hour) and severe (as greater than 30 events per hour) ${ }^{20}$.

\section{Statistical analysis}

For all statistical tests we adopted the significance level of 5\%. Data were initially tested through Kolmogorov-Smirnov test to determine whether distribution was normal or not. To verify the relationship between numerical variables with normal distribution test we used the Pearson correlation test, while the Spearman rank correlation test was applied to non-parametric variables. To check the proportion in each level of categorical variables we used Chi-Square Pearson. SPSS 18.0 was used to perform data analysis. To investigate the existence of differences between cognitive performance of OSA patients and controls we used statistical tests for independent samples. The tests used were Student's t test for variables with normal distribution and Wilcoxon test otherwise.

\section{RESULTS}

The average time for administration of the cognitive tests and the ESS was 30 minutes. During the recruitment period 26 patients were submitted to cognitive testing and underwent polysomnography in the clinic. Of these, 17 were diagnosed with OSA, being still untreated, and were selected for the study. Among the remaining cases, two had OSA under CPAP treatment, four had primary snoring and two cases had inconclusive results, and were thus excluded from the analysis.
Among the study patients, eight (47.1\%) were diagnosed with severe OSA, five (29.4\%) with moderate OSA and four (23.5\%) with mild OSA.

For the control group, 20 healthy individuals adequately matched for age, gender and education with the OSA patients were evaluated. Table 1 displays the main sociodemographic and anthropometric characteristics of patients and controls.

MMSE scores were higher among controls than among OSA patients. In DST, the performance of OSA patients and controls were similar with respect to hits, but the former group had significantly lower scores in the total number of cells satisfied, but committed fewer errors. In the BCSB, controls performed significantly better than OSA patients in incidental memory, immediate memory, learning and delayed recall. No significant differences emerged between the two groups on category fluency and clock drawing. In FAS, controls produced a significantly higher number of words beginning with letters $\mathrm{A}$ and $\mathrm{S}$, accounting for a higher total score in the test. Table 2 shows the results of OSA patients and controls in the cognitive tests.

\section{DISCUSSION}

In the present study, which did not use sophisticated methods of investigation, we found that performance of OSA patients was impaired in comparison to healthy controls in tests assessing attention, graphomotor speed, memory, language and executive functions. Hence, a variety of cognitive domains seems to be affected in this condition and brief cognitive testing may detect such changes.

In DST, OSA patients were slower than controls, although presenting fewer errors. The small sample size may be responsible for this unexpected finding and needs further exploration. As for episodic memory, the performance of the OSA group in the BCSB was also impaired in relation to controls in four different measures, namely, incidental memory, immediate memory, learning and recall. Finally, in the FAS test patients produced fewer words that their counterparts.

Table 1. Main sociodemographic and anthropometric characteristics of OSA patients and controls.

\begin{tabular}{lccc}
\hline & OSA & Controls & $p$ \\
\hline Age (years) & $41.4 \pm 13.0$ & $27.6 \pm 8.7$ & 0.74 \\
Educational level (years) & $11.5 \pm 3.8$ & $13.3 \pm 3.8$ & 0.18 \\
BMI & $30.4 \pm 7.0$ & $23.2 \pm 1.8$ & $<0.01$ \\
Neck circumference (centimeters) & $41.9 \pm 4.2$ & $35.5 \pm 2.2$ & $<0.01$ \\
ESS & $12.2 \pm 5.2$ & $5.1 \pm 2.1$ & $<0.01$ \\
\hline
\end{tabular}

OSA: Obstructive Sleep Apnea; BMI: Body Mass Index; ESS: Epworth Sleepiness Scale. Data represent mean \pm standard deviation. 
Table 2. Performance of OSA patients and controls in the cognitive tests.

\begin{tabular}{lccc}
\hline Cognitive test & OSA & Controls & $p$ \\
\hline MMSE & $28.0 \pm 1.3$ & $29.1 \pm 0.9$ & 0.01 \\
DST (Total) & $42.1 \pm 14.8$ & $52.2 \pm 13.3$ & 0.04 \\
DST (Errors) & $0.3 \pm 1.5$ & $0.9 \pm 1.2$ & 0.05 \\
DST (Hits) & $41.9 \pm 15.4$ & $51.2 \pm 13.0$ & 0.04 \\
BCSB incidental recall & $5.4 \pm 1.5$ & $7.4 \pm 1.0$ & $<0.01$ \\
BCSB immediate recall & $7.9 \pm 1.3$ & $8.7 \pm 1.0$ & 0.02 \\
BCSB learning & $8.8 \pm 1.0$ & $9.6 \pm 0.7$ & 0.01 \\
BCSB delayed recall & $8.2 \pm 1.6$ & $9.1 \pm 1.0$ & 0.02 \\
Category fluency (animals) & $17.8 \pm 5.3$ & $20.0 \pm 4.3$ & 0.18 \\
Clock drawing & $8.9 \pm 1.7$ & $9.4 \pm 0.5$ & 0.26 \\
FAS - F & $15.3 \pm 4.3$ & $15.8 \pm 2.9$ & 0.68 \\
FAS - A & $12.5 \pm 3.4$ & $15.6 \pm 2.9$ & 0.01 \\
FAS - S & $13.0 \pm 3.9$ & $15.6 \pm 2.8$ & 0.02 \\
FAS Total & $40.8 \pm 10.4$ & $47.0 \pm 6.6$ & 0.03 \\
\hline
\end{tabular}

OSA: Obstructive Sleep Apnea; MMSE: Mini-Mental State Examination; DST: Digit-Symbol Test; BCSB: Brief Cognitive Screening Battery; FAS: Phonemic Verbal Fluency (letters F-A-S). Data represent mean \pm standard deviation.

The impact of OSA on cognitive performance may provide additional parameters to monitor clinical improvement after therapeutic interventions. Attention, episodic memory and executive function tests rank among the tools which may be useful in this context. Moreover, the MMSE, a brief and global measure of cognitive functioning, may also depict some changes in these patients, although scores obtained in the OSA group were within the normal limits for the Brazilian population.

Previous studies investigating cognitive performance in patients with OSA have been able to distinguish the impairment resulting from EDS from that determined by chronic obstructive pulmonary disease, which traditionally assumes the occurrence of ischemic prefrontal lesions ${ }^{21-23}$.

Yaouhi and colleagues submitted 16 patients with OSA to neuropsychological testing and functional neuroimaging. Although the authors did observe only little deficits in the functions assessed (mainly memory and motor function), functional brain changes could be detected, suggesting that such modifications precede the clinical manifestations ${ }^{22}$.

One study conducted in Finland with 40 newly diagnosed OSA cases and 20 healthy controls also found impaired performance of the former in some neuropsychological tests, such as the copy of the Rey figure, Block Design and Trail Making $\mathrm{B}^{24}$. In a subsequent study, this same group of investigators demonstrated that even prolonged CPAP treatment was not able to match the performance of both groups, especially in learning tasks ${ }^{25}$.

We believe that the demonstration of cognitive im- pairment, even being of mild severity, is enough to motivate further studies aiming at elucidating the etiology of these deficits. Despite that researchers still fail to reach a consensus on the issue EDS versus neuronal damage, the mere possibility of irreversible brain damage associated with a highly prevalent and often underestimated medical problem is an alarming feature. The latest observations on neuronal death associated with intermittent hypoxia in animal models of OSA and functional neuroimaging studies in humans help to understand the nature of injuries, leading to speculation about strategies to halt or even to reverse this process ${ }^{26,27}$. A better understanding of the mechanisms of neuronal dysfunction or cell death that may occur in OSA might bring benefits to these patients.

Screening methods for OSA should be inexpensive. ESS, available in a validated version in Portuguese for use in Brazil is an appropriate use for this purpose and has an excellent cost-benefit profile as well as being easy and quick to administer ${ }^{17,18}$. The limitations related to the subjectivity of the answers provided to questions from the ESS can only be overcome at the moment with the use of objective tests to measure sleepiness, as the multiple sleep latency test, the gold standard for this diagnosis. However, this procedure is not effective in the context of screening because of its high cost and difficulty of large-scale application. The infrastructure required for the test is better used if dedicated to diagnostic confirmation through polysomnography performed in individuals identified with EDS in the ESS ${ }^{19}$.

With respect specifically to OSA, screening in the 
outpatient setting is a simple task that requires a brief clinical history and the assessment of good clinical predictors, such as ESS score, neck circumference and $\mathrm{BMI}^{6,10}$. Moreover, the use of standardized cognitive tests in the context of Sleep Medicine, in addition to the other above-mentioned measures, could contribute to a more accurate assessment of OSA, since it would offer objective information on the clinical consequences of the syndrome.

In conclusion, we found that OSA was responsible for deficits in attention, memory and executive functioning. Objectively, OSA patients presented signs of reduced information processing speed, a decrease in learning and delayed recall and also an impairment in phonemic verbal fluency. These findings are in line with the international literature on the subject. However, the limitations of the present study did not permit speculation about the etiology of these cognitive deficits.

\section{REFERENCES}

1. McCarthy ME, Waters WF. Decreased attentional resposivity during sleep deprivaion: orienting response latency, amplitude, and habituation. Sleep 1997;20:115-123.

2. Engle-Friedman M, Riela S, Golan R, et al. The effect of sleep loss on next day effort. J Sleep Res 2003;12:113-124

3. Rodenstein D. Sleep apnea: traffic and occupational accidents - individual risks, socioeconomic and legal implications. Respiration 2009;78:241-248.

4. Rakel RE. Clinical and societal consequences of obstructive sleep apnea and excessive daytime sleepiness. Postgrad Med 2009;121:86-95.

5. Irwin MR, Carrillo C, Olmstead R. Sleep loss activates cellular markers of inflammation: sex differences. Brain Behav Immun 2010:24:54-57.

6. Panossian LA, Avidan AY. Review of sleep disorders. Med Clin North Am 2009:93:407-425

7. Punjabi NM. The epidemiology of adult obstructive sleep apnea. Proc Am Thorac Soc 2008:5:136-143.

8. Yaggi HK, Strohl KP. Adult obstructive sleep apnea/hypopnea syndrome: definitions, risk factors and pathogenesis. Clin Chest Med 2010;31:179-186.

9. Freedman N. Treatment of sleep apnea syndrome. Clin Chest Med 2010; 31:187-201.
10. Chan A, Kushida C. Sleep-disordered breathing. Continuum Lifelong Learning Neurol 2007;13:139-152.

11. Sánchez Al, Martínez P, Miró E, Bardwell WA, Buela-Casal G. CPAP and behavioral therapies in patients with obstructive sleep apnea: effects on daytime sleepiness, mood, and cognitive function. Sleep Med Rev 2009; 13:223-233.

12. Chuah LY, Chee MW. Functional neuroimaging of sleep deprived healthy volunteers and persons with sleep disorders: a brief review. Ann Acad Med Singapore 2008;37:689-694

13. Lezak MD. Orientation and attention. In: Lezak MD (Ed). Neuropsychological Assesment. New York: Oxford University Press, 1995:381-384.

14. Folstein MF, Folstein SE, McHugh PR. "Mini-mental state": a practical method for grading the cognitive state of patients for the clinician. J Psychiatr Res 1975;12:189-198.

15. Brucki SM, Nitrini R, Caramelli P, Bertolucci PH, Okamoto IH. Sugestões para o uso do mini-exame do estado mental no Brasil. Arq Neuropsiquiatr 2003; 61:777-781.

16. Vitiello AP, Ciríaco JG, Takahashi DY, Nitrini R, Caramelli P. Avaliação cognitiva breve de pacientes atendidos em ambulatório de neurologia geral. Arq Neuropsiquiatr 2007;65:299-303.

17. Johns MW. A new model for measuring daytime sleepiness: the Epworth Sleepiness Scale. Sleep 1991;14:540-545.

18. Bertolazi AN, Fagondes SC, Hoff LS, Pedro VD, Menna Barreto SS, Johns MW. Portuguese-language version of the Epworth sleepiness scale: validation for use in Brazil. J Bras Pneumol 2009;35:877-883.

19. Kushida CA, Littner MR, Morgenthaler T, et al. Practice parameters for the indications for polysomnography and related procedures: an update for 2005. Sleep 2005:28:499-521.

20. Jafari B, Mohsenin V. Polysomnography. Clin Chest Med 2010;31:287-297.

21. Wise MS. Objective measures of sleepiness and wakefulness: application to the real world? J Clin Neurophysiol 2006;23:39-49.

22. Yaouhi K, Bertran F, Clochon $\mathrm{P}$, et al. A combined neuropsychological and brain imaging study of obstructive sleep apnea. J Sleep Res 2009;18:36-48.

23. Verstraeten E, Cluydts R, Pevernagie D, Hoffmann G. Executive function in sleep apnea: controlling for attentional capacity in assessing executive attention. Sleep 2004;27:685-693.

24. Saunamäki T, Himanen SL, Polo O, Jehkonen M. Executive dysfunction in patients with obstructive sleep apnea syndrome. Eur Neurol 2009;62: 237-242.

25. Saunamäki T, Himanen SL, Polo O, Jehkonen M. Executive dysfunction and learning effect after continuous positive airway pressure treatment in patients with obstructive sleep apnea syndrome. Eur Neurol 2010;63:215-220.

26. Lavie L. Sleep-disordered breathing and cerebrovascular disease: a mechanistic approach. Neurol Clin 2005;23:1059-1075.

27. Desseilles M, Dang-Vu T, Schabus M, Sterpenich V, Maquet P, Schwartz S. Neuroimaging insights into the pathophysiology of sleep disorders. Sleep 2008;31:777-794. 